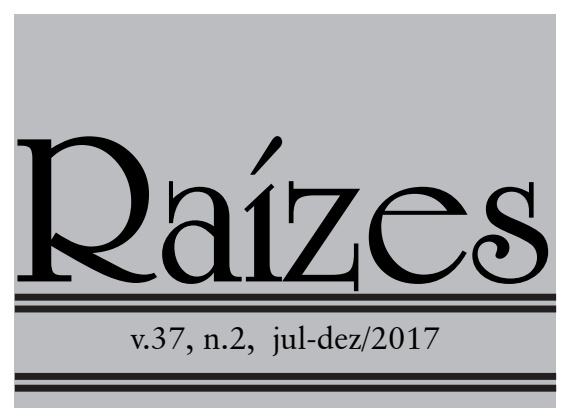

\title{
AS DISPUTAS PELA ATIVIDADE APÍCOLA NO SERTÃO DO PIAUÍ ${ }^{6}$
}

\author{
May Waddington Telles Ribeiro
}

\section{RESUMO}

A apicultura no sertão nordestino se inicia com a chegada da abelha africanizada à região onde índios e camponeses tradicionalmente extraíam o mel de melíponas e trigonas para alimentação da família. No esforço de domesticação da apis melifera, atores com distintas racionalidades econômicas e ambientais formaram uma rede produtiva, comercial e técnica na qual há uma significativa dependência do empresário por parte do pequeno produtor. A flora da Caatinga se revela um pasto apícola espetacular e essa indústria ganha visibilidade quando, em 2003, o preço do mel se quadruplica no mercado internacional. O governo estadual promove investimentos na atividade, introduzindo novos critérios de eficiência e de gerenciamento na rede produtiva, gerando disputas pelos canais de beneficiamento e comercialização na competição pelo mercado internacional. Este se aquece de sobremaneira em torno do mel, agora valorizado enquanto orgânico, sustentável e socialmente justo. O presente artigo analisa o desenvolvimento da rede, identificando os diferentes atores envolvidos e as disputas e diferenças entre suas visões de desenvolvimento e sustentabilidade, considerando o período de 2003 a 2011.

Palavras-chave: Desenvolvimento; Apicultura; Modernização; Economia Camponesa Redes de Comercialização.

\section{THE STRUGGLES FOR THE CONTROL OF THE BEEKEEPING ACTIVITY IN THE PIAUI STATE}

\section{ABSTRACT}

Commercial beekeeping in the Brazilian northeastern hinterland begins with the arrival of the Africanized bee to the region where indians and peasants traditionally extracted honey from native stingless bees. In an effort to domesticate the Apis bee, actors with distinct economic and environmental rationalities form a production, trade and technical network in which there is a significant dependence of the small producers in relation to the entrepreneurs. The caatinga flora turns into a spectacular pasture and the honey industry gains visibility when, in 2003, the product price quadruples in the international market. The state government promotes investments in the activity, introducing new standards of efficiency and management into the network, generating disputes around the processing marketing channels, as well as for the organic and fair trade international market that had already been established. This article identifies the different actors involved, conflicts and differences in their visions of development and sustainability in the 2003-2011 period.

6 Esse artigo é fruto de pesquisas financiadas pelo CAPES através do PROGRAMA DE COOPERAÇÃO ACADÊMICA NOVAS FRONTEIRAS (PROCAD-NF 2009), que patrocinou o Programa de Pesquisas Dinâmicas Sociais e Ruralidades Contemporâneas. Também recebeu financiamento, inicialmente, de uma bolsa do CNPQ, através do Programa de Desenvolvimento Científico Regional (DCR-CNPQ), de 2007 a 2008.

Professora permanente no Programa de Pós-Graduação em Estado Sociedade da Universidade Federal do Sul da Bahia. E-mail: may.waddington@gmail.com. 
Keywords: Development; Modernization; Peasant Economy; Commercial Networks. INTRODUÇÃO

Durante a espetacular florada da caatinga piauiense no inverno de 2003, os produtores de mel da região foram surpreendidos pela exuberante quadruplicação no preço do seu produto no comércio internacional ${ }^{7}$, impulsionado pela rejeição aos meles argentino e chinês, contaminados por agrotóxicos e antibióticos, respectivamente. Em duas viagens a campo nos anos de 2003 e 2004, as entrevistas com sertanejos recentemente inseridos na atividade produtiva flagrava a feliz surpresa com os rendimentos auferidos que representaram uma transformação sensível na capacidade de consumo de suas famílias.

Diversos comerciantes procuravam, febrilmente, controlar os pontos chaves da rede comercial que as novas oportunidades oferecidas pela indústria do mel constituíam, em um apressado e competitivo processo de disputa por um novo território que era, ao mesmo tempo, concreto e abstrato. Era concreto por depender da natureza física - desde flores, pólen, abelhas, a instrumentos de coleta como baldes, caixas de abelha e máquinas centrífugas - e abstrato, por não depender da propriedade da terra, uma vez que as abelhas não são limitadas por cercas, não coincidindo o local das colmeias com aquele das flores visitadas. A disputa que se travava era pela rede de relações sociais, naturais e técnicas que constituem o território por onde se pretendia expandir8.

A apicultura se mostrava renitente à colonização ou monopólio na medida em que o controle de colmeias de abelhas agressivas não podia ser incrementado infinitamente. Um produtor familiar normalmente manejava de 10 a 50 caixas de abelha, enquanto que os que conseguiam se organizar em grandes redes familiares alcançavam maiores quantidades (de quinhentas a mil caixas). O papel do pequeno produtor nessa cadeia é dificilmente suprimido, desvalorizado ou transformado em trabalho assalariado. Assim, o empresariado procurava formas de controlar a rede em formação, experimentando desde fórmulas antigas e consagradas no sertão do patronato - a meagem, parcerias e cobrança de renda - às inovadoras cooperativas de diferentes tipos.

Havia, ainda, atores institucionais atentos às oportunidades sociais e políticas abertas pela indústria de produção do mel e pela rede comercial que se formava em torno da mesma. O presente artigo investiga esse universo, refletindo sua diversidade, ao descrever empreendimentos diferentemente orientados, em especial, as primeiras atividades apícolas no Piauí, iniciadas por uma família de migrantes paulistas; a cooperativa organizada por um padre diocesano que atuava há décadas na região; e uma cooperativa de segundo grau montada por técnicos e agentes do desenvolvimento regional do governo do PT eleito em 2002, que promoveu a construção de laboratórios e a assistência técnica com o intuito de modelar o futuro da atividade econômica.

O governo estadual, em estreito alinhamento com o governo federal, usufruiu das políticas de transferência de renda como também de programas de fortalecimento da agricultura familiar - entre os quais, a distribuição de casas de mel na região de Picos e São Raimundo Nonato. $\mathrm{O}$ ambiente federal era propício ao nordeste, favorecendo a articulação entre as agências de fomento dos mais variados tipos ${ }^{9}$. Neste momento, sob a égide do discurso do Desenvolvimen-

7 O quilo do mel, na mão do produtor, subira de oitenta centavos para quatro reais, tendo chegado a atingir R4,50, no ápice do pico. Era vendido em latões de vinte quilos, para diferentes tipos de intermediários, conforme examinaremos mais adiante.

8 Neste trabalho, estaremos, propositalmente, evitando descrever as relações sociais que se estabelecem e modificam pelo termo "Arranjo Produtivo Local", para tentarmos analisar DESTACAR NA ANÁLISE, PERMITINDO QUE SE ENXERGUE PARA enxergar além da atividade econômica que a sigla APL cristaliza.

9 Analisamos, em outra parte, o início do primeiro mandato do Presidente Lula marcado por um messianismo carismático nos quais ventos de inovação pareciam suspender a ordem histórica, criando condições para grandes apostas em novos ciclos de riqueza econômica, como a malfadada aventura do biodiesel no sertão, celebrada pelo I Congresso Internacional de Agrocombustíveis realizado em Teresina, Piauí (Waddington, 2009). A atenção privilegiada do governo federal ao nordeste representava novos tempos de oportunidade de acesso a recursos públicos que inserissem a região "abandonada" no projeto 
to, diferentes interesses e propostas de futuro para o Estado do Piauí se apresentavam, se posicionavam e acionavam recursos diferentemente acumulados, em uma espécie de tabuleiro de jogo disposto sobre um campo de estratégias que se alteraria rapidamente nos anos subsequentes.

Ao longo da década que se seguiu, conforme o programa de pesquisas intitulado "Dinâmicas Sociais e Ruralidades Contemporâneas" se estabeleceu ${ }^{10}$, percebemos como a observação desse universo multifacetado favorecia a análise das formas como o Estado articulava diferentes instituições e estendia seu aparato burocrático-administrativo orientado por preceitos da racionalidade de econômica, sobre uma realidade histórica e socialmente construída que era orientada por outras racionalidades (no caso, a camponesa e a católica).

Ao nos propormos desenvolver estudos na área da Antropologia do Desenvolvimento, rejeitamos a definição da mesma enquanto antropologia aplicada, nos mantendo na esfera analítica da atividade. Adotamos, porém, uma abordagem metodológica específica, ancorando nossa análise em dados etnográficos colhidos localmente, por um lado e, por outro, na observação de atores e agentes institucionais, buscando os sentidos e significados que orientam as formas como estes exercem seu poder.

Assim, ao direcionarmos nossa prática antropológica ao conjunto de propostas de desenvolvimento em ação no Piauí, entendemos que devemos buscar na formação discursiva os elementos constitutivos de uma ordem (Escobar, 1995) que organiza os esforços institucionais e constrói uma rede de atores posicionados assimetricamente em um campo (Ribeiro, 2009) no qual se estabelece uma correlação de forças a fixar prioridades e conduzir decisões que impactam fortemente a vida de populações locais (Peet, 1999) cuja cultura construiu e foi construída em contato estreito com seus territórios (Almeida, 2008). Repensar a dualidade rural/urbano contribui para percebermos a imbricação, no mesmo espaço físico, de diferentes esferas de atividade (agrícola-apícola sendo ao mesmo tempo comercial-industrial-científica) através de relações assimétricas que estão em constante transformação (Carneiro, 2012).

Se conseguimos apreender diferentes núcleos ideacionais na análise comparativa das racionalidades e visões de mundo operacionalizadas pela cooperativa (organizada por um padre) e aquela empregada no centro tecnológico (financiado por agentes articulados pelo governo estadual), precisamos insistir na observação etnográfica para compreender como se mobilizaram os posicionamentos do governo do Piauí no campo do desenvolvimento no período em estudo, marcado pela coincidência entre os governos petistas estadual e federal, e os rumos que estas favoreceram ao longo da década ${ }^{11}$.

Acreditamos que a análise de conjuntura se transforma em antropologia ao admitir a existência de auto definições regionais coletivamente construídas, analisando como estas orientam o comportamento de indivíduos que ocupam postos nas instituições. Deste ponto de vista, na medida em que a ordem discursiva conforma a identidade de atores regionais, define suas motivações e estratégias em relação ao "estar dentro" ou "estar fora” dos grandes programas econômicos ${ }^{12}$, que são, eles próprios, ocasionados pelo conjunto de enunciados agregados sob

nacional. (Waddington, 2011). O ambiente institucional estimulado no período possibilitou a articulação aqui estudada.

10 Uma parceria entre PPGANT/UFPI e o CPDA/UFRRJ, financiado pela CAPES através do PROCAD N.F, o programa gerou o Grupo de Pesquisas em Antropologia do Desenvolvimento e Meio Ambiente no Piauí (Grupo ADMA), que promoveu inúmeros trabalhos de campo entre 2007-2012, gerando dissertações e teses.

11 Esse questionamento aproxima dois ângulos da antropologia do desenvolvimento e do meio ambiente como a esfera de conceituação principal do programa de pesquisa realizado pelo Grupo ADMA, na convergência entre a vinculação genealógica do desenvolvimento com os grandes projetos de engenharia (Ribeiro, 2000) e, por outro, a geração de identidades motivada pelo conflitos advindos dos grandes projetos (Fox 1996, Almeida 2008, Acselrad 2008).

12 Para Escobar, ao verem a si próprios como subdesenvolvidos, agentes locais passam a se de-sub-desenvolverem através da submissão às intervenções externas sistematicamente planejadas e executadas, com a consequente destruição de seu tecido social e autonomia com o comprometimento de sua identidade. O próprio reconhecimento de determinadas condições 
o termo genérico “desenvolvimento”. As formas específicas de auto definição regional determinam adesões, ações, políticas, escolhas e investimentos que, mesmo quando voltados para o mercado, são mediados e negociados na relação entre as regiões/territórios com o Estado, entre as instituições político-administrativas "de fora" e "de dentro". Assim, a esfera burocrático -administrativa é sociedade, objeto de estudo etnográfico.

Para tanto, tomamos a sociedade local como composta por interesses e racionalidades múltiplas e dissonantes. Desta forma, a grande ordem discursiva que dispõe os programas de desenvolvimento não é determinada apenas de cima (Estado) para baixo (região), ou de fora (capital internacional ou nacional) para dentro (território), mas a partir de determinados segmentos da sociedade local que ocupam (ou se opõe aos que ocupam) cargos, estabelecem alianças, acionam recursos e exercem influência para "cima”, para "dentro" e para "fora”, de acordo com o que internalizaram no seu processo de auto definição em relação à ordem discursiva do Desenvolvimento Nacional.

\section{O CENÁRIO - DA IMAGEM AO IMAGO}

O sertão nordestino se configurou no imaginário brasileiro - através da literatura regionalista das décadas de 40-60 e do noticiário sobre as grandes secas - como a região do isolamento e da miséria. Durante o período (30-60) de urbanização e conquistas de direitos trabalhistas e sociais a provocar grandes mudanças na sociedade brasileira, cristalizou-se a visão do nordeste como região do atraso. Nesse imaginário, lá, onde um povo sofrido e ressequido travava lutas sem trégua contra o solo pobre, a vegetação hostil e a terrível e impiedosa seca que os condenava à fome endêmica, uma oligarquia atrasada e desumana reproduzia situações de exploração medievais.

Mesmo enquanto a face agrária do País se modernizava com a abertura incessante de fronteiras agrícolas, os biomas da caatinga e do cerrado nordestino eram tidos como desprovidos de valor, repousando como uma triste reserva esquecida pela marcha do desmatamento e da agricultura mecanizada que destruía, sequiosa, grandes áreas de cerrado do Planalto Central e partes da Amazônia. Durante as décadas de 60-90, esse processo tanto técnico-econômico quanto político-administrativo que se materializou na chamada "revolução verde" 13 , ainda não tinha utilidade para as terras secas do sertão. Como, durante o ciclo desenvolvimentista do período de ditadura ${ }^{14}$ este adquiriu um caráter emblemático do desenvolvimento desejado pelo "Brasil que vai pra frente", sua ausência nas vastas regiões do sertão nordestino reforçou a imagem de atraso e pobreza, levando importantes contingentes dessas sociedades a se verem como “excluídos” da nova conformação de projeto nacional.

(como a pobreza ou o atraso) desses países como "problemas", aciona especialistas e políticos e constrói um novo domínio de saber e de experiência que acaba por colonizar a realidade, determinando estratégias para se lidar com tais "problemas", terminando por criar, de fato, realidades aceitas e internalizadas pela população - tal como o conceito homogeneizado e universalizado de "Terceiro Mundo". Esta produção de discurso - sob condições desiguais de poder - cria sujeitos e objetos, reformadores e reformados, permitindo que os primeiros exercitem poder sobre os segundos. Assim se gera uma clientela (muitas vezes involuntária) de estratégias de intervenção (Escobar, 1995).

13 Processo de modernização da agricultura, que intensifica a produção de commodities de exportação através de uso intensivo de maquinário agrícola, sementes modificadas e extensionismo rural especializado na promoção desta tecnologia como o plantio direto que favorecem uma atividade com uso intensivo de agrotóxicos e baixa absorção de mão de obra.

14 "foi, sobretudo a partir dos anos de 1970 - com a política de "modernização da agricultura" promovida pelo regime militar -, que se começou a falar mais explicitamente da existência de uma "agricultura moderna" ou de uma "agricultura capitalista" no Brasil”... Para uma descrição da evolução dos termos agricultura moderna, complexo agroindustrial e agronegócio, ver esse artigo Sociedade do Agronegócio, de Palmeira, Herédia e Leite, 
Atualmente, até essas brasileiríssimas fronteiras interiores têm sido acessadas. Na última década, o Piauí se transformou em uma espécie de “cerrado da vez" com a expansão da fronteira da soja a partir do Maranhão sobre o sudoeste do Piauí e a partir do noroeste baiano pelo seu extremo sul; a aquisição de 160 mil hectares de terra pela Suzano Celulose para o monocultivo de eucaliptos e malfadados esforços no sentido da produção de biocombustíves a partir da mamona (Waddington, 2009). A região da caatinga, palco principal da atividade apícola no Piauí, com grandes plantios de caju, começa a ser devastada na medida em que é atravessada pela ferrovia Transnordestina e nela são instalados projetos de mineração.

Entrevistamos, em 2005, distribuidores de mel em Mineápolis, EUA, a receber a mercadoria da COMAAPI, localmente conhecida como a "cooperativa do padre" por ter sido fundada por um padre diocesano. Relataram a importância do produto para o novo consumidor "consciente" que exigia a certificação do Mercado Justo que comprovasse um valor social assim como a certificação orgânica. Era justamente por ter ficado fora do processo de modernização da agricultura e sua transformação em atividade capitalista (entrevista C.A. e T.B., Mineapolis, 2005) que este produto agregava, naquele momento, um alto valor de mercado.. Era justamente a exclusão que proporcionava a inserção do Piauí no sistema-mundo através de um produto com diferencial considerado luxuoso (um mel orgânico, puro, limpo). Aquilo que havia sido considerado remoto e pobre adquiria outro significado diante de alterações na visão de mundo dos consumidores assustados com os riscos invisíveis da poluição e contaminação pós-modernas (Beck, 1999).

A vegetação da caatinga, de pobre e rústica, passa a ser vista como limpa e pura, por ser isenta de poluição química. As abelhas que pastam em suas imensas floradas produzem um mel livre dos perigos da modernidade, auferindo um valor de mercado inédito. No entanto, para que isso fosse possível, a produção local precisou se adaptar às inúmeras exigências de controle de qualidade e rastreabilidade que a certificação envolve, exigindo a abertura de livros, transparência na produção e a verificação laboratorial da qualidade do produto, que representa uma racionalização cada vez mais profunda, disciplinando uma produção que, na ponta inicial, continua camponesa. Cria-se, assim, um movimento de mão dupla, pelo qual o capitalismo avançado estende suas carências ao que estava "fora" de si, considerado atrasado, primitivo e pobre, e que passa a ser visto como "puro e prístino", ao mesmo tempo em que civiliza tais regiões "selvagens" com sua incorporação ao sistema de controle burocrático de rastreabilidade dos SIFs da Anvisa, certificados de produto orgânico e de comércio justo.

No sentido inverso das alterações no mercado externo, ocorrem importantes transformações locais decorrentes de processos históricos e paulatinos da extensão da infra-estrutura do desenvolvimento sobre a região. Mesmo lentas, tais mudanças são cumulativas e alteram a condição de "atraso", também do ponto de vista político. Ao mesmo tempo em que é alcançada pela tecnologia das comunicações com seus fortes efeitos sobre a capacidade de comercialização e erradicação de intermediários free-riders, a construção da rede viária alterou de forma concreta o caráter "remoto" da região. A possibilidade de trânsito minou o controle político coronelista sobre bens e serviços públicos, desestabilizando as antigas estruturas comerciais associadas à patronagem.

Houve um fluxo de duas gerações de nordestinos a participarem da construção de grandes obras de infraestrutura em outras partes do País a partir dos anos 50. Além de alterarem a face física da modernização da sociedade brasileira com seu trabalho braçal nas cidades e barragens de todo o País, esse movimento trouxe um retorno cultural e econômico às famílias que permaneceram no local (Waddington, 2010) ao mesmo tempo em que introduzia referenciais culturais nos centros nacionais. O conjunto dessas modificações historicamente geradas como 
efeito do processo de desenvolvimento capitalista, criou também as condições políticas para a ascensão do PT em 2002, como primeira experiência de governo popular no Estado do Piauí.

O compromisso do governo Lula com o Piauí foi sacramentado no dia seguinte à posse, com a viagem à Guaribas para a inauguração do seu projeto-ícone da fase inicial de seu governo, o Fome Zero. Através desse gesto simbólico, o primeiro presidente operário e migrante nordestino assumia publicamente o compromisso com uma ideia de desenvolvimento voltado para a superação da pobreza nas regiões remotas e rurais do país. Ao mesmo tempo, cristalizava o sertão da pobreza, do isolamento e do atraso, como um símbolo da realidade a ser superada.

Argumentamos aqui que o sertão não se resume à pobreza. Abriga diferentes formas tradicionais de ocupação do território que desenvolveram, ao longo de inúmeras gerações, formas de manejo de recursos naturais através de lavouras, extrativismo, pequenas criações e pecuária em pequena escala com a variedade e multifuncionalidade característica da economia camponesa. Tais sistemas de vida desenvolvidos através do saber local, criaram formas de sociabilidade e manifestações culturais que não se reduzem à experiência de penúria. As formas tradicionais de uso e manejo de recursos garantem determinados graus de resiliência diante do flagelo da seca, mas também garantem alguma autonomia em relação à instabilidade de ciclos econômicos, políticos e sociais que impactam tais comunidades.

O "Governo do Desenvolvimento" de Wellington Dias ${ }^{15}$ se apresentou como uma novidade política importante na história local, promovendo uma renovação de quadros que envolveu a absorção de lideranças do movimento social. A circulação da elite política piauiense facilitou a modernização administrativa, imprimindo eficiência gerencial, planejamento estratégico e o investimento na promoção profissional da imagem do estado, um conjunto de medidas que criou melhores condições de possibilidade para a instalação do agronegócio no Estado. Rapidamente, a prioridade do desenvolvimento se deslocou do combate à pobreza para a atração do grande capital e dos grandes projetos de infraestrutura a partir do PAC. ${ }^{16}$.

\section{O MEL NO PIAUÍ}

O uso do mel de abelhas nativas brasileiras na alimentação tradicional foi registrado em relatos de viajantes (Gardner, 1975) e nas primeiras etnografias realizadas no Piauí (Carneiro, 1976). As abelhas nativas melíponas e trigonas eram abundantes na região, tanto em quantidade como em diversidade. Desde pequeníssimas abelhas solitárias a colmeias construídas como delicadas rendas e estruturas arquitetadas dentro de troncos ou a metros de profundidade no solo, encontra-se tiúbas, jandaíras, mangangás, uruçus, munduris, moças brancas... As famílias sertanejas consomem rotineiramente o mel como produto do extrativismo, tendo desenvolvido também formas de criação de abelhas domésticas como as tiúbas (Melipona compressipes) mantidas em caixas penduradas no quintal, chamadas localmente de cortiços. Atualmente, pequenos agricultores, assustados com a rapidez com que as abelhas nativas desaparecem, discu-

15 Governador do PT entre 2002-2010, Wellington Dias ascendeu do sindicato dos bancários aos cargos de vereador, deputado estadual e federal ao de governador, sendo então eleito Senador em 2010 e retornando ao governo em 2014. É, no entanto, importante para o nosso estudo, o fato de sua eleição em 2003 ter sido a primeira eleição de um governo popular na história do estado do Piauí e desta ter coincidido com a eleição de Lula ao governo federal, como já comentamos.

16 Internamente, articulava-se um conjunto de obras de infraestrutura necessárias para atrair investimentos e promovia-se ações institucionais facilitadoras, tais como a regularização fundiária pelo Instituto de Terras do Piauí, de forma a gerar as condições de confiança em possíveis investidores e compradores externos. Externamente, investia-se em esforços de marketing, como a exposição de produtos em feiras nacionais e internacionais e a contratação de uma grande firma de assessoria de imprensa profissional que possibilitou aparições do estado em programas televisivos de prestígio. Em 2004 o Piauí figurou como palco da visita de um personagem de telenovela a uma fábrica de bicicletas, imprimindo uma imagem de atividade industrial ao estado, promovendo o sítio turístico de Sete Cidades como cenário de um encontro amoroso. Poucos meses depois, o programa Mais Você, veiculou uma série promocional sobre o Piauí. Em ambas o merchandizing, era patentemente estatal. 
tem as causas do sumiço das abelhas nativas, atribuídas ao desmatamento, à utilização indiscriminada de agrotóxicos ou à entrada da abelha do gênero Apis ${ }^{17}$.

Das 400 espécies de abelhas sem ferrão que existem no planeta, 360 são nativas no Brasil e povoaram nossas matas, ocupando-se silenciosa e constantemente do trabalho de polinização, construindo a imensa biodiversidade brasileira. Desta forma, a importância das abelhas indígenas extrapola utilidade econômica e invade a esfera de bens coletivos, na medida em que são vitais para a polinização, tanto da flora selvagem quanto a cultivada. Sua diminuição ou desaparecimento acarretam enorme risco para a humanidade.

A abelha da espécie Apis mellífera chegou ao Brasil em 1835, oriunda da península Ibérica através do padre Antônio Carneiro e, por imigrantes da Alemanha (1845) e Itália (1870) que se estabeleceram no sul do país. Mais produtivas do que as espécies nativas, as Apis se prestavam à exploração doméstica e comercial. Entre os imigrantes que conheciam as práticas apícolas, estava a família austríaca dos Wenzel que se estabeleceram na região de Ribeirão Preto em São Paulo, produzindo mel em uma atividade comercial familiar que incluía três gerações. Formavam uma coletividade composta pelo patriarca, filhos e esposas, cunhados e irmãos, netos, sobrinhos e bisnetos que tinham a produção e a comercialização do mel da Apis como principal fonte de renda. Apesar de a apicultura envolver atividades comerciais e semi-industriais e apesar da agricultura ser uma atividade secundária, o grupo preserva características de família camponesa, dividindo as tarefas de produção e comercialização entre homens, mulheres e crianças, com grande coesão interna ${ }^{18}$.

$\mathrm{Na}$ década de 50, doenças dizimaram grande parte da população das Apis, comprometendo $80 \%$ da produção nacional. O governo brasileiro solicitou ao geneticista Dr. Warwick Kerr que trouxesse exemplares de rainhas do gênero Apis de uma espécie africana cuja resistência e produtividade o cientista estudava. Acidentalmente, algumas rainhas escaparam do laboratório em Rio Claro, SP, em 1957. Iniciou-se um rápido processo de cruzamento com a espécie Apis mellífera europeia, gerando a feroz abelha africanizada com os diversos incidentes mórbidos divulgados internacionalmente. Nas décadas subsequentes, a produção apícola comercial brasileira, conforme praticada pela família Wenzel, ficou praticamente inviabilizada.

Algum tempo depois, cargas de mel começaram a chegar do Nordeste para serem comercializados no sudeste. Arlindo, um dos irmãos da terceira geração dos Wenzel, resolveu investigar de onde vinha aquela produção. Seguiu os caminhões que entregavam o produto e descobriu as extensas floradas da caatinga a servirem do mais excelente pasto melífero possível. Organizou sua família nuclear, que migrou com ele para Picos em 1975, onde se estabeleceram até trazer, paulatinamente, diversos outros irmãos e sobrinhos. Por volta de 1980, dois caminhões de caixas de abelha e equipamento, seguidos por mais dois veículos, trouxeram uma boa parte do clã dos Wenzel que se rendiam aos pastos apícolas da caatinga piauiense.

Além de se instalarem como produtores de mel, os cinco diferentes irmãos Wenzel que vivem no Piauí se especializaram na fabricação de caixas; na extração e processamento de cera de abelha e geleia real; na montagem de uma indústria de envaze; na elaboração de uma variedade de produtos compostos de mel com própolis, agrião e outros produtos naturais; em uma firma de exportação; e na organização de grandes migrações sazonais em caminhões próprios. Seus filhos e netos casaram localmente, a grande família se expandiu mantendo vínculos estrei-

17 Em visitas a laboratórios na UFC e no INPA em Manaus, entomologistas demonstraram que as nativas - apesar de conhecidas como abelhas sem ferrão - não se intimidam diante das Apis e as atacam com suas fortes mandíbulas. Para estes cientistas, o desmatamento é a principal responsável pela diminuição desta população.

18 A família Wenzel nos recebeu por diversas vezes ao longo de 2003 a 2008, concedendo inúmeras entrevistas e depoimentos, cedendo materiais em vídeo do período de mudança para a região. As informações desse relato advêm desse conjunto de entrevistas e depoimentos, em especial, de seu Arlindo Wenzel. 
tos que permitem que administrem um número bem maior de caixas de abelha próprias do que outros produtores (mais de mil caixas por família).

O clã dos Wenzel foi a principal origem do conhecimento, agora amplamente difundido na região, sobre o manejo racional das abelhas afro-européias, fonte de toda a indústria local. Conforme o velho pioneiro afirma:

Eu fui o culpado, viu? Não sei nem de onde tirei a coragem para fazer isso tudo: trazer a família para tão longe, naquele tempo. Mas era mel demais! Florada boa demais! Depois os irmãos vieram, os filhos foram fazendo amizade... acabaram casando! Mas eu fui o culpado. O povo fica vendo onde os Wenzel vão porque sabem que onde eles vão o mel vai estar! E ficam seguindo a gente, vindo atrás! ${ }^{19}$

\section{A EXPANSÃO PAULATINA DO APINEGÓCIO NA REGIÃO}

Há dúvidas entre cientistas quanto ao arrefecimento paulatino da agressividade da abelha africanizada pela sua adaptação após algumas gerações de miscigenação, ou se houve uma adaptação das populações locais às mesmas. Porém, acima de tudo, o que permitiu o convívio e formas de manejo das abelhas africanizadas foi o desenvolvimento tecnológico que resultou do trabalho científico em universidades, contando com a consultoria de criadores como os Wenzel, cuja experiência e conhecimento empírico contribuíram para a elaboração de vestimentas, caixas e técnicas de manejo.

O fato, nessa história cheia de consequências inesperadas, é que além de maior produtividade e resistência a doenças, a agressividade que restou às abelhas africanizadas revelouse providencial. Na medida em que dificultava o roubo de colmeias, tornava-se útil ao manejo por parte de famílias de agricultores em áreas extensivas do sertão. O conhecimento básico da apicultura racional começou a se difundir a partir dos Wenzel em Picos, se expandindo para os municípios de Simplício Mendes, Oeiras, São Raimundo Nonato, entre outros. Em 1983, entre 30 e 40 produtores em Picos se reuniram para comprar insumos, equipamentos, e para comercializar conjuntamente seus produtos fundando a cooperativa CAMPIL $^{20}$.

Em 1990, o Banco do Nordeste investiu através do $\mathrm{FNE}^{21}$ nos municípios de Picos, Simplício Mendes e São Raimundo Nonato, e diversas cooperativas se formaram, concorrendo entre si. A CAMPIL se caracterizava por trabalhar apenas com grandes produtores (com

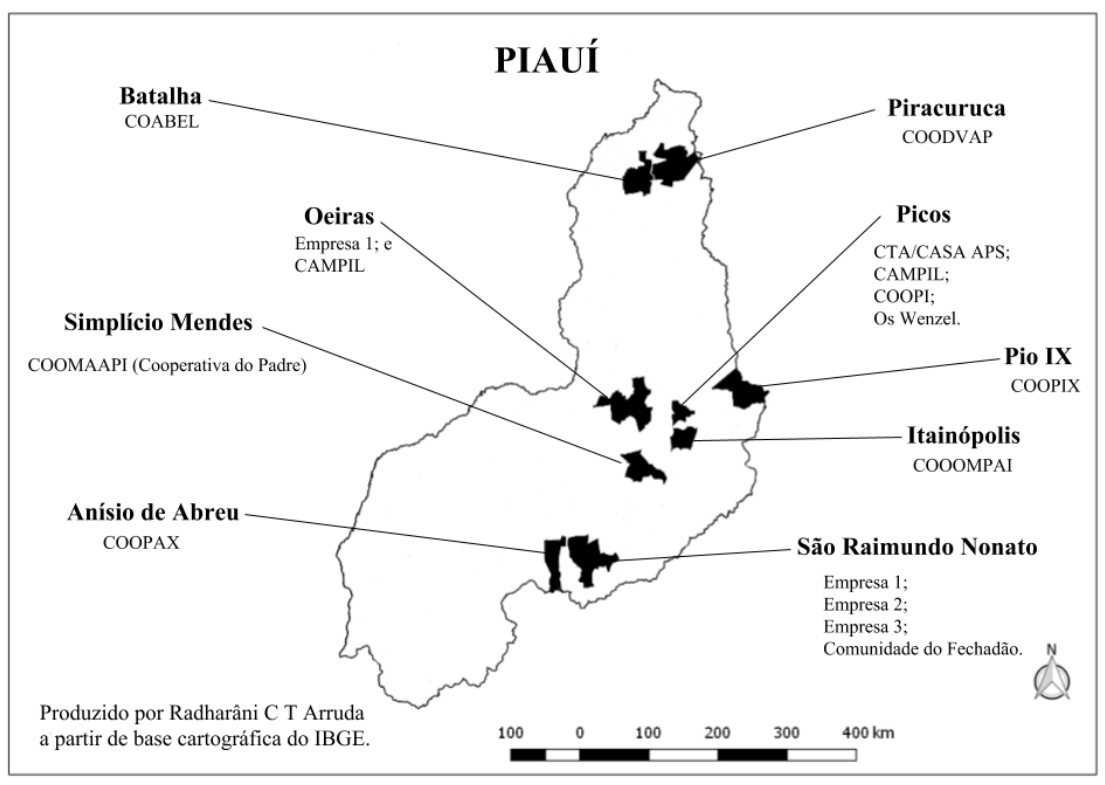

19 A.W., Entrevista em vídeo, novembro de 2003, Picos

20 A primeira das cooperativas de apicultores na região, fundada em Picos,

21 Programa Fomento do Banco do Nordeste através do Financiamento às Microempresas e Empresas de Pequeno Porte e ao Empreendedor Individual (FNE-MPE) 
500 a 800 colmeias) e restringiam a entrada de produtores menores. Surge então a COAPI, em Picos, enquanto a COOVAI e a COOPI também se instalam na microrregião de Picos, COOPIX (Pio IX), COMPAI (Itainópolis), COOPAX (Anísio de Abreu), enquanto que em Simplício Mendes a "Cooperativa do Padre" (COMAAPI) se especializava nas comunidades produtoras. No norte do estado surgiram a COODEVAPI (Piracuruca) e COABEL (Batalha).

O relato de um produtor de Oeiras, sócio fundador da CAMPIL, demonstra como mesmo sem possuir as terras onde o mel era explorado, este estabelecia a divisão dos resultados com os camponeses a quem emprestava o equipamento apícola (roupas, caixas, quadros, fumegador, garfo, latões e acesso à centrífuga) adaptando o código tradicional de relações de patronagem nas quais o proprietário da terra e seus meeiros dividiam a produção. Dessa forma, observamos como a histórica separação entre quem tem terra e quem não a tem é traduzida, aqui, na relação entre quem tem recurso a um pequeno capital e quem não tem recurso a nenhum, seja por dificuldades de acesso físico (estradas) ou institucional (financiamento), é o que permite reproduzir as formas mais tradicionais de exploração do trabalho no sertão ${ }^{22}$.

Com a alta do preço do mel e o ambiente institucional que prometia a atenção dirigida dos bancos de fomento locais, uma gama variada de empreendedores, tanto locais como de outros estados, apressava-se em ocupar os nós da rede que se articulava velozmente, procurando modernizar a relação tradicional de trabalho no sertão.

Um jovem e ambicioso empresário, também de Oeiras, transformou a marcenaria de seu pai em fábrica de caixas de abelha e quadros de cera, fundando uma empresa exportadora com uma agressiva estratégia de compra dos maiores volumes possíveis na região de São Raimundo Nonato, competindo com outras duas empresas que lá operavam. Em 2004, a empresa instalara um grande armazém e casa do mel nesta cidade, comprara frota de veículos e caminhões e intermediava o financiamento da produção entre o Banco do Brasil e os produtores familiares ao tempo em que fornecia implementos. Em 2008, quando retomamos a pesquisa, essa empresa havia fechado devido a uma quebra no sistema de financiamento junto ao banco. De acordo com o gerente de uma cooperativa, entrevistado em 2009, o fracasso desta aventura se deveu ao alto endividamento do empresário no momento do "boom", com a grande alta do preço, quando chegou a estocar 17 mil latões de mel. Tendo ficado refém da dívida, foi incapaz de pagar tão bem aos produtores quanto seus competidores, quando preço do mel voltou à normalidade (entrevista JM, setembro 2009).

$\mathrm{Na}$ ponta destes esforços estavam as famílias camponesas do sertão, agora classificadas pelas agências de fomento como agricultores familiares. Ficavam, assim, passíveis de receber financiamentos pelo Pronaf ${ }^{23}$, mas tinham dificuldades de acessar tais recursos, necessitando da intermediação oferecida por empresários. No período da grande alta, entre 2003 e 2004, tais famílias se integravam à rede da forma como podiam. No entorno do Parque Nacional da Serra da Capivara, em São Raimundo Nonato, por exemplo, havia um grande número de famílias produzindo individualmente ou em pequenos núcleos, cuja produção era disputada por diferentes empresas ou atravessadores tanto do Piauí quanto do Ceará ou mesmo de São Paulo, que competiam por seus latões de mel. Registramos uma família de idosos em uma estrada de difícil acesso, há $40 \mathrm{~km}$ de São Raimundo Nonato que, em seu pequeníssimo puxadinho, extraía mel em uma centrífuga improvisadamente operada pelo casal e por um filho adulto, recém retornado de São Paulo. Dispunham-se a vender ao primeiro que aparecesse com um bom preço. Haviam se equipado precariamente com recursos de suas aposentadorias. A nova atividade

22 Para uma descrição detalhada, ver a etnografia de Maria José Carneiro na qual diferentes arranjos de parceria entre parceiros, meeiros, agregados, vizinhos, moradores, vaqueiros são descritos em uma colônia de assentamento organizada em Colônia do Gurguéia (Carneiro, 1976).

23 O Programa Nacional de Fortalecimento da Agricultura Familiar que era estendido aos agricultores através do Banco do Nordeste ou Banco do Brasil com baixas taxas de juros 
era complementar à roça e à pequena criação, mas auferia uma renda, na ocasião, significativa a ponto de atrair um filho adulto de volta de São Paulo.

Já a comunidade do Fechadão ${ }^{24}$, em São Raimundo Nonato, apresentava uma produção coletiva bem organizada. Seu líder, Procópio, era então presidente do Sindicato dos Trabalhadores Rurais em S. Raimundo Nonato. Após um treinamento ministrado por um extensionista de Floriano, diferentes famílias dominaram a técnica de manejo e extração em uma casa de mel coletiva, conseguindo negociar um preço melhor ao negociar conjuntamente o produto aos intermediários.

\section{A COOPERATIVA DO PADRE - COOMAAPI}

No Município de Simplício Mendes, havia uma rede de comunidades nas quais, por mais de duas décadas, o padre Geraldo Gereon, ligado à Diocese de Oeiras, desenvolvia atividades sociais como a construção de cisternas, pequenas barragens, estradas em locais estratégicos, abrigo de idosos e outras ações assistenciais com recursos que levantava no sudeste do País e no exterior. Fundou, em 1994, a cooperativa AAPI (Associação de Apicultores da Micro Região de Simplício Mendes) envolvendo 125 famílias em diversas comunidades. Conseguiram verbas do CCPR (Coordenação de Combate à Pobreza Rural, financiado pelo Banco Mundial através da Secretaria do Planejamento do Estado) para financiar a instalação de casas de mel em sete comunidades e a Diocese estendeu a ação a 25 outras ao longo do tempo. Em 2003, por ocasião de nossa primeira visita, a Cooperativa atendia a 27 comunidades. Em 2009, eram 32 comunidades associadas com 1100 famílias beneficiadas desde o início do programa, 930 destas ligadas à COOMAPI ${ }^{25}$. Em 2013, ocasião de minha última visita, estavam presentes em 36 comunidades.

Em cada comunidade a casa de mel era instalada, quatro ou seis famílias recebiam dez caixas de abelhas, indumentárias e apetrechos, cujo valor era restituído para serem estendidos às próximas comunidades. A cooperativa não financiava projetos individuais, tendo as comunidades que formar associações com coordenadores eleitos para receberem a casa de mel e o treinamento. As unidades de beneficiamento eram inauguradas com cerimônias públicas nas quais havia missa e trabalho espiritual. Para padre Geraldo ${ }^{26}$, a atividade apícola era apenas a primeira de um processo de organização social. As atividades de caprinocultura, criação de galinhas caipiras e ovinos, assim como hortas comunitárias. eram também fomentadas.

A cooperativa, instalada em Simplício Mendes, possuia área de armazenagem, laboratório de controle de qualidade, escritório, equipamento de filtragem, de produção de blends e de embalagem em capsulas e em latões, sistema de compra coletiva e distribuição de roupas e equipamentos, transporte próprio. Mais importantemente, desenvolveu contato com importantes parceiros, construindo a capacidade de certificar o produto das comunidades através do SIF, o Selo de Inspeção Animal requerido pelo Ministério de Agricultura, além da certificação orgânica do Instituto Biodinâmico e do selo do Mercado Justo. Com isso, a possibilidade de exportação estava garantida já em 2004. Iniciaram-se as vendas diretas de mel para a Itália e Estados Unidos através da rede de comércio justo, em um volume que atingiu 114 toneladas em 2005

24 Fundada na década de 50 em uma experiência pioneira de colônia de assentamento rural de iniciativa do localmente conhecido padre Lira. É provável que o diferencial de capital social apresentado por esta comunidade em termos do acesso ao sindicato e a recursos institucionais, se deva à singularidade de ter nascido de um esforço organizado e da experiência que adquiriu a partir disso.

25 Enrevista Paulo José, em Simplicio Mendes, setembro 2009

26 que depois de 34 anos na paróquia de Simplício Mendes, pediu para ser transferido para São Francisco de Assis do Piauí onde reinicia seus trabalhos (entrevista em São Francisco do Piauí, julho 2011) 
(Fortes, 2009). Em 2009, as vinte e cinco mil colmeias distribuídas produziam 250 toneladas de mel que eram exportadas em 13 containers. Em 2011 a produção subiu para 411 toneladas.

Ao visitarmos, em 2004, a comunidade associada de Betânia em um assentamento do INCRA, percebemos que além do incremento na renda, a alegria com que compartilhavam um jornal na qual saíra uma notícia a seu respeito indicava a importância do reconhecimento externo para o grupo. O incremento da autoestima proporcionada pelo papel de facilitador de acessos da cooperativa ia além dos financiamentos e certificados. A reunião, que se deu na igreja, sem a presença do padre mas mesmo assim em meio a rezas, indicava o grau de envolvimento do catolicismo no processo de organização interna da comunidade.

Em 2009, visitamos a comunidade de Patos, então recentemente inserida nos trabalhos da cooperativa e que apresentava a especificidade de ser composta exclusivamente de brancos da família Coelho ${ }^{27}$ - com diversos sinais de problemas genéticos possivelmente derivados de casamentos entre parentes. No processo de adesão à cooperativa, o padre exigiu que a comunidade abdicasse da proibição de entrada de negros, permitindo que estes frequentassem as festas da comunidade. Isso demonstra uma intervenção no campo da moral, que se situa fora da esfera da racionalidade econômica, pertencendo à esfera da religiosidade do padre que via como normal esse tipo de cobrança a quem se candidatava a benefícios articulados por ele, em nome da igreja. A entrevista com o gerente da cooperativa, em 2009, revelou uma política clara da cooperativa pela qual os associados não deveriam apenas esperar auferir benefícios econômicos, mas deveriam “acreditar em Deus” e aceitar outros preceitos tais como a justiça social, igualdade e fraternidade entre os homens, além da preservação da natureza.

\section{A CTA/CASA APIS: CENTRAL DE COOPERATIVAS APÍCOLAS DO SEMI-ÁRIDO}

Em 2000, a ideia de uma Central de Cooperativas foi apresentada ao então deputado Wellington Dias. Quando eleito governador, este procurou despertar o interesse dos Ministérios de Integração e de Ciência e Tecnologia. Em 2004, promoveu uma reunião entre as cooperativas do Norte e Nordeste com IICA-Holanda ${ }^{28}$, que forneceu o capital inicial para a instalação de um centro de comercialização, para a construção de um grande desumidificador e laboratório de controle de qualidade. Nascia, assim, o Centro de Tecnologia Apícola que fornece os serviços de incubadoras de negócios através de assistência técnica, uma minifábrica de colmeias, macacões, máscaras, fumegadores, fabricação de compostos, processamento de pólen, própolis, geleia real e apitoxina. Vinculada ao CTA, se instala, em 2005, o seu braço cooperativo, a CASA APIS, com a distribuição de 20 casas de mel e a filiação de cooperativas: CAMPIL, Mel COOPI (Picos), COOPIX (Pio IX), COMPAI (Itainópolis), COOPAX (Anísio de Abreu), além de COODEVAPI (Piracuruca) e COABEL (Batalha) ao norte do estado.

O investimento inicial feito pelo IICA-Holanda foi da ordem de R\$ 700 mil. A Fundação Banco do Brasil investiu 140 mil em um diagnóstico e 2 milhões em equipamentos, veículos e estrutura física; o SEBRAE ${ }^{29}$ investiu 3 milhões em capacitação e participações em fei-

\footnotetext{
27 Foi a primeira incursão do grupo a uma comunidade de "coelhos". Uma entrevista subsequente com um líder quilombola na região indicou um interessante fenômeno de relações inter-raciais no Piauí, pelo qual atribuía genericamente o nome "Coelho" a brancos de comunidades que se recusam a interagir com a população mestiça. O trabalho de dissertação de Cinthya Kós, uma das integrantes do grupo, sistematiza a etnicidade deste grupos de brancos descendentes da família Coelho que se acamponesaram e se isolaram em diversos pontos do sertão e dos cerrados do Piauí e, aparentemente Bahia, reunindo as características de isolamento e endogamia, racismo e alto grau de controle interno. Na região, o termo "coelho" se refere a tais grupos que são considerados arredios e feios, estranhos e tímidos. (Kós, 2014).
}

28 Interamerican Institute for Cooperation on Agriculture

29 Serviço Brasileiro de Apoio às Micro e Pequenas Empresas que compõe o "Sistema S" que reúne nove instituições de interesse de categorias profissionais (SESC, SENAC, SENAI, SENAR, SEST, SENAT, SESCOOP e SESI, e o próprio SEBRAE) que 
ras e eventos; a CODEVASF ${ }^{30}$ investiu 1,4 milhões na construção do laboratório do CTA e R\$ 300 mil em compra de colmeias totalizando em torno de $\mathrm{R} \$ 7,5$ milhões de investimento inicial. O Governo do Estado comprou diretamente 70 toneladas de mel para a merenda escolar.

Esse conjunto de financiamentos e apoios criava condições para que o novo governo reivindicasse sua participação em uma atividade econômica que já vinha construindo sua base produtiva e redes de comercialização. Restava saber quais atores seriam fortalecidos nesse processo, acessando os benefícios ou o controle da rede, na nova disposição que essa articulação produziria com seus enunciados e racionalidades específicas. De acordo com as declarações contidas no material institucional e nas entrevistas efetuadas, a inserção estratégica dessa articulação no setor visava a otimização da produção, através do controle de qualidade, treinamento, profissionalização e venda coletiva através da construção de uma instância de assistência técnica pública que beneficiaria a economia regional de forma geral, promovendo o desenvolvimento.

Inicialmente, antigos atores como os Wenzel e a Cooperativa do Padre (a COOMAPI) dispensavam, educadamente, essa colaboração, alegando não ter necessidade da mesma e até 2011 não utilizavam estes serviços. Nos primeiros anos os pequenos produtores da região vendiam seus latões de mel a quem pagasse o melhor preço à vista, se recusando a dar tratamento preferencial à Casa Apis. Até 2009, percebemos uma atitude de frustração e ressentimento por parte dos administradores desta última, que consideravam a atitude como falta de visão empresarial. Assim, a Casa Apis não conseguiu gerar o volume de estoque necessário à exportação.

Uma consultoria contratada à Fundação Getúlio Vargas pela Fundação Banco do Brasil identificou que, mesmo com as boas intenções da Casa Apis de substituir os atravessadores e produzir um mel de boa qualidade, a estrutura gerencial distanciava os produtores que não se sentiam "donos” da cooperativa. De uma forma característica de projetos organizados "de cima para baixo", um dos técnicos nos alegou terem estado tão ocupados com a grandeza do empreendimento que haviam "se esquecido dos pequenos produtores"31.

A Fundação Banco do Brasil, uma das principais financiadoras, condicionou a continuidade de sua participação à solução desta falha. Articulou-se a criação de um subprojeto intitulado "Informe Cooperar", que investia em ações de comunicação junto a Agentes de Desenvolvimento Regional Sustentáveis (ADRS) capacitados pelo Sebrae, visando aproximar as comunidades da Casa Apis, através de oficinas onde eram "discutidos os conceitos de cooperativismo para construir um sentimento de pertencimento" 32.

Estes problemas foram superados pelo corpo de gerentes, contadores, secretários, assessores e consultores, mantidos com o financiamento anual na ordem de 1,5 milhão pela FBB e com o apoio do Sebrae. Se em 2005, ano em que conseguiram o SIF do Ministério da Agricultura, a Casa Apis só conseguiu produzir 2 containers, em 2009 já havia em torno de 800 produtores associados, dos quais 350 estavam certificados como orgânicos pelo IBD e 250 em vias de certificação ${ }^{33}$. A metade era de pequenos produtores camponeses, com menos de vinte colmeias, sendo uma pequena quantidade com mais de duzentas colmeias. Alcançavam, então, os 14 containers que os equiparavam finalmente à produção da Cooperativa do Padre, de Simplício Mendes. Em 2011 a produção já dispunha de certificações do Fair Trade, E.R., IBD orgâni-

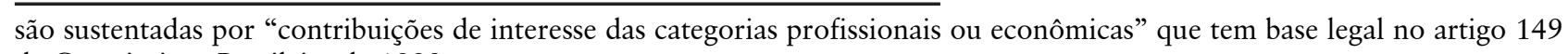
da Constituição Brasileira de 1988.

30 Companhia de Desenvolvimento do Vale do São Francisco.

31 Entrevista F.2., outubro 2009, Teresina.

32 Entrevista F.1, setembro 2009, Teresina.

33 O faturamento das exportações em 2008 foi de US\$ 498271,00, em 2009 US\$ 751.731,00 e em 2010 571046,00. 
co, tendo participado da feira de orgânicos internacional Biofach na Alemanha onde fecharam uma grande venda para a Itália.

Em fevereiro de 2011, uma reunião de Planejamento Estratégico da Casa Apis reuniu alguns de seus principais parceiros e financiadores (FBB e SEBRAE e representantes das comunidades). Diversos especialistas vindos de Brasília e de Teresina ajudavam a localizar gargalos de produção, tais como a necessidade de se estimular a demanda interna, embalagens, rotulagem, etc., enquanto procuravam a forma de autonomizar o empreendimento, prevendo o momento de sustar o apoio a fundo perdido, de 1,5 milhão anuais.

A participação das comunidades estava representada no evento por produtores e por um grupo de aproximadamente 10 jovens Agentes de Desenvolvimento Regional (ADRS) apoiados pelo Sebrae e Senai. Estes "técnicos por afinidade" eram escolhidos pelas 22 comunidades participantes, entre seus membros cooperados. Os produtores recebiam financiamento pelo PRONAF A e B, porém considerava-se que algumas comunidades começariam a requerer o PRONAF C e D por já terem incrementado bastante a renda e as condições de vida locais. Os municípios aderiam ao Garantia Safra, e o Banco do Brasil financiava através de Adiantamentos de Crédito (ACC).

O presidente do sistema CTA-Casa APIS é, simultaneamente, Presidente da Federação das Entidades Apícolas, órgão de representação público e privado. No entanto, existem outras entidades que reúnem atores da rede comercial, tais como a ABIMEL, associação dos exportadores de mel, e empresas exportadoras como a PRODAPYS (a maior exportadora do Brasil). Ambas acusavam a Casa Apis de estar inflacionando o mercado, pagando mais do que outras cooperativas certificadas. Outras cooperativas menores se ressentiam do controle pretendido pela estratégia da Casa Apis, que sugeria que seu sistema gerencial substituísse os seus contadores individuais ${ }^{34}$. A disputa com a CAMPIL - a grande cooperativa de Picos que abrigava grandes produtores - e a COOAPI, também de Picos, chegou a extremos, com acusações frente ao Ministério Público em 2008 e corte total de relações em 2011.

\section{CONSIDERAÇÕES FINAIS}

A ordem discursiva do Desenvolvimento se volta para um cliente-problema contra o qual organiza a rede de agentes e instituições produzidas por esta ordem. O compromisso com a erradicação da pobreza em determinada região aciona recursos através de políticas públicas orientadas pela interpretação prevalecente de pobreza. Dependendo desta interpretação, tais recursos serão usados para fortalecer a autonomia proporcionada por sistemas de vida camponeses ou para superá-los através de formas de inclusão social que os desarticulem. Se a economia camponesa é confundida com a pobreza ocasionada pela falta de infraestrutura e alcance de políticas públicas, a racionalidade que orientará as instituições será no sentido de sua erradicação e não de seu fortalecimento. Nas duas experiências examinadas, agentes institucionais (padre e consórcio) seguiram diferentes orientações na construção de redes de produção e comercialização do mel.

Nossas observações revelaram que a racionalidade adotada pela COMAAPI prioriza o fortalecimento da autonomia produtiva camponesa, investindo em outras atividades como a caprinocultura e plantio de roças. Já a Casa APİS privilegia a inserção no mercado e a captura

\footnotetext{
34 A cultura gerencial da Casa Apis segue uma orientação autoritária, na qual a noção de profissionalismo se confunde com uma impessoalidade que destoa de tudo o que se vê no Piauí, principalmente no interior do estado e no meio rural. De uma forma um tanto ingênua, segue-se um modelo semelhante ao do SEBRAE por onde os mecanismos de comunicação são embebidos de uma ritualística que não existe mais no mundo corporativo, tais como o hábito de secretárias "passarem a ligação" de acordo com a hierarquia dos executivos a bordo, etc.
} 
dos nós da rede de compra e revenda, da mesma forma que das empresas privadas ou as tentativas de colonização por parte dos atravessadores, mesmo que declare objetivos orientados ao bem público. A valorização de atitudes "profissionais" vistas como libertadoras de um estado de pobreza e atraso, se traduzem em vários sinais de absorção naturalizada da ideologia de mercado, como expressa no vocabulário de técnicos do SEBRAE que afirmam terem "formatado" os produtores camponeses, ou do então Governador Wellington Dias que, em visita oficial no auge da crise de fornecimento à Casa Apis, repreendeu os camponeses por não abandonarem a caprinocultura e o "policultivo" para se concentrarem na atividade da apicultura. ${ }^{35}$.

A moralidade dos técnicos da Casa Apis interpreta como opressoras as ingerências do padre na vida privada de seus cooperados, revelando a estreita ligação entre o ideário iluminista que prega o laicismo e condena propostas de envolvimento moral e espiritual em atividades de mercado. Essa moralidade considera o trabalho de base que prioriza a autossuficiência do sistema de vida camponês estimulando a caprinocultura e outras atividades que compõe esse sistema, por parte do padre, como um atraso. Outro dado revelador da crítica de um ideário ao outro é a forma como a negativa do padre em adotar uma perspectiva de crescimento infinito da produção, era vista como uma falta de ambição com conotações imorais. A carga fortemente emotiva que acompanha os comentários dos executivos do consórcio CTA/APIS, demonstra que sua visão burocrática-administrativa se mostra tão dogmática quanto o discurso religioso.

Os técnicos da COMAAPI, por sua vez, assumem com tranquilidade que o trabalho que executam não se restringe ao incremento de renda. Para fazer parte da cooperativa os associados têm que "acreditar em Deus", preservar a natureza e, como vimos, ceder a alguma pressão moral e cívica do padre como no caso da comunidade que proibia a entrada de negros em suas festas e famílias (Ent. P.J., set 2009).

O discurso desenvolvimentista que se apresentou no cenário da pesquisa no Piauí possui dois matizes que se confundem, embora apresentem uma diferença sutil e tenha consequências muito diferentes: a solução da pobreza e a inclusão da região (Estado do Piauí) no cenário da modernidade nacional. No primeiro, o apoio a pequenos produtores de forma a fortalecer sua autonomia é contemplado. Já quando o desenvolvimento se ressemantiza como a inclusão do Estado no conjunto da nação através da integração ao mercado internacional, essa autonomia é facilmente sacrificada, como se as formas de vida camponesas fossem a própria causa da exclusão da região. No entanto, nosso estudo demonstrou que a riqueza gerada pelo mel decorreu justamente deste não ter sido explorado pelo modelo racional que produziu a revolução verde.

Os atores que ocupam posições estratégicas nas instituições que fomentam o desenvolvimento, no Piauí, se apresentaram, muitas vezes, como motivado por feridas morais originadas no preconceito sentido no contato com o resto da nação. Neste caso, favorecem o objetivo da equiparação e superação do "atraso" de uma forma que dificulta a percepção das especificidades da produção local, a resiliência destes pequenos produtores face à seca e às possibilidades de um desenvolvimento com base no convívio o semiárido. Se a impossibilidade de se eliminar o pequeno produtor familiar na cadeia de produção do mel apareceu como o grande fator que impediu a colonização pura e simples da atividade por parte da rede orientada pela racionalidade mercantil das cooperativas primitivas, os milhões investidos na manutenção do consórcio CTA/Apis para "corrigir" aquilo que já vinha sendo construído pela cooperativa do padre, a Coomaapi, demonstra uma lógica de colonização institucional que resolve o problema da pobreza - senão erradicando o pobre, “contornando--o" para neutralizar os seus efeitos - ao invés de fortalecer a economia camponesa.

35 Entrevista F.1, setembro 2009 
Assim, concluímos que é essa segunda interpretação contida no termo desenvolvimento enquanto inclusão nacional, a forma que favorece as decisões que cedem a chantagens locacionais, abrindo o território piauiense para o grande capital, sem respeitar a vocação local interna e as estratégias econômicas historicamente construídas.

Recebido em: 05/06/2017

Aprovado em: 13/10/2017

\section{REFERÊNCIAS}

Acselrad, Henri. Cartografia Social e Território. Rio de Janeiro: IPPUR/UFRJ, 2008.

Acselrad, Henri e Bezerra, G. N.- Desregulação, deslocalização e conflito ambienta, in Capitalismo Globalizado e Recursos Territoriais, Rio de Janeiro, Ed. Lamparina, 2010

Almeida, Alfredo Wagner Berno de, Terras Tradicionalmente Ocupadas: Terras de Quilombo, Terras Indígenas, Babaçuais Livres, Castanhais Do Povo, Faxinais e Fundos De Pasto. 2. ed. Manaus: Editora da Universidade do Amazonas, 2008.

. Agroestratégias e desterritorialização: direitos territoriais e étnicos na mira dos estrategistas do agronegócio. In Capitalismo globalizado e recursos territoriais. Rio de Janeiro: Lamparina, 2010, p. 101-144

Beck, Ulrich, 1999, World Risk Society, Polity Press, London.

Carneiro, Maria José. 1976, Terra da pobreza: um estudo antropológico de uma comunidade rural piauiense. Dissertação [1976] 190f. (Museu Nacional-Universidade Federal do Rio Janeiro-UFRJ). Rio de Janeiro:

Sociedade Brasileira -Ed.Mauad, Rio de Janeiro

org. 2012, Ruralidades Contemporâneas - Modos De Viver E Pensar O Rural Na

Escobar, Arturo, 1995, "Encountering Development, the making and unmaking of the Third World", Princeton University Press, New Jersey, USA

2001Culture sits in places: reflections on globalism and subaltern strategies of localization. In http://www.unc.edu/ aescobar/html/texts.htm

Fox, Jonathan 1996 "How does Civil Society Thicken? The Political Construction Of Social Capital in Rural Mexico", in World Development, Vol24, No. 6, pp1089-1103, Elsevier Science Ltd, UK

GARDENER, George. Viagens ao interior do Brasil: principalmente nas províncias do Norte e nos distritos do ouro e do diamante durante os anos de 1836-1841. Belo Horizonte: Itatiaia. São Paulo: Ed. da USP, 1975.

Jameson, Frederic, Pós Modernismo: A Lógica Cultural do Capitalismo

Tardio, ed. Ática, São Paulo 1996

Peet, Richard, and Hartwick, Elaine, Theories of Development, 1a edição, Guilford Publications, New York, EUA, 1999

Ribeiro, Gustavo Lins, Cultura e Política no Mundo Contemporâneo, Brasília, ed. Universidade de Brasília, 2000

Waddington, M.T.R, A Cajuína Cristalina em dois diferentes momentos do processo de modernização do Piauí, Anais ALASRU, VIII Congresso Latino Amreicano de Sociologia Rural, Nov. 2010. 